\title{
El papel del derecho comunitario andino en la temática del medio ambiente desde las competencias de los municipios*
}

[Artículos]

\author{
Edwin Francisco Antolinez Sánchez ${ }^{* *}$
}

Recibido: 5 de agosto de 2020

Aprobado: 13 de octubre de 2020

Citar como:

Antolínez Sánchez, E. F. (2021). El papel del derecho comunitario andino en la temática del medio ambiente desde las competencias de los municipios. Revista IUSTA, (54). https://doi.org/10.15332/25005286.6554

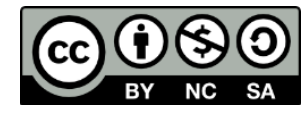

\section{Resumen}

Teniendo en cuenta la importancia de la relación generada entre los cuatro ordenamientos jurídicos de la Comunidad Andina (CAN) y, por supuesto, de Colombia desde la correcta aplicación de políticas públicas

\footnotetext{
* El presente manuscrito es producto del proyecto de investigación: "Las decisiones y resoluciones emitidas por la Comunidad Andina (CAN) en el marco de protección de derechos del medio ambiente en los municipios", gestionado en el marco de la Maestría en Derecho Administrativo en la Universidad Libre (Sede Bogotá).

** Administrador Público egresado de la Escuela Superior de Administración Pública Territorial Boyacá Casanare - CETAP Tunja, Abogado egresado de la Universidad Santo Tomás Seccional Tunja y Magister en Derecho Administrativo de la Universidad Libre (Sede Bogotá - Colombia). ORCID: http://orcid.org/0000-0002-3710-8010. Correo electrónico: edwinfranciscoantolinez@gmail.com
} 
que propendan por la protección y conservación del medio ambiente por parte de los municipios, el presente artículo pretende destacar el papel del derecho comunitario andino en la temática del medio ambiente desde las competencias de los municipios. De este modo, el artículo desarrolla las siguientes temáticas: 1 ) la naturaleza jurídica del derecho comunitario andino; 2) para qué sirve y por qué existe el derecho comunitario andino; 3) el marco normativo de la CAN y de Colombia referente al medio ambiente en los municipios, y 4) el papel, la importancia y la finalidad del derecho comunitario andino en relación con el medio ambiente frente a los municipios. Consecuentemente, el problema de investigación planteado se basa en la siguiente pregunta: del papel del derecho comunitario andino en la temática del medio ambiente busca generar impacto positivo o negativo desde las competencias de los municipios? Para el efecto, se considera que el marco normativo de los municipios no atiende las decisiones supranacionales de la CAN desde la perspectiva medioambiental.

Palabras clave: derecho comunitario andino, medio ambiente, municipios.

\section{The role of Andean Community law in environmental issues from the authority of the municipalities}

\section{Abstract}

Taking into account the importance of the relationship generated between the four legal systems of Andean Community (CAN) and, of course, of Colombia from the correct application of public policies that promote the protection and conservation of the environment by the municipalities, this article aims to highlight the role of Andean Community law in the environmental issues from the authority of the municipalities. Therefore, this article develops the following topics: 1) the legal nature of Andean Community law; 2) what is Andean Community 
law for and why does it exist? 3) The regulatory framework of the Andean Community $(C A N)$ and Colombia regarding the environment in the municipalities, and 4) the role, importance and purpose of the Andean Community law with regards to the environment in relation to municipalities. Consequently, the research problem posed is based on the following question: does the role of Andean Community law in environmental issues seek to generate positive or negative impact from the authority of the municipalities? To this effect, it is considered that the regulatory framework of the municipalities does not attend the supranational decisions of the $C A N$ from the environmental perspective.

Keywords: Andean Community law, environment, municipalities.

\section{O papel do direito comunitário andino na temática do meio ambiente a partir das competências dos municípios}

\section{Resumo}

Considerando a importância da relação gerada entre quatro ordenamentos jurídicos da Comunidade Andina (CAN) e da Colômbia, com base na correta aplicação de políticas públicas que propendem pela proteção e pela conservação do meio ambiente por parte dos municípios, neste artigo, pretende-se destacar o papel do direito comunitário andino na temática do meio ambiente a partir das competências dos municípios. Desse modo, neste artigo, são desenvolvidas as seguintes temáticas: 1) natureza jurídica do direito comunitário andino; 2) para que serve e por que existe o direito comunitário andino; 3) o referencial normativo da CAN e da Colômbia sobre o meio ambiente nos municípios; 4) o papel, a importância e a finalidade do direito comunitário andino com relação ao meio ambiente ante os municípios. Nesse sentido, o problema de pesquisa proposto está baseado na pergunta: o papel do direito comunitário andino na temática do meio ambiente procura gerar impacto positivo ou negativo a partir das competências dos municípios? 
Para isso, é considerado que o referencial normativo dos municípios não atende às decisões supranacionais da CAN sob a perspectiva meio ambiental.

Palavras-chave: direito comunitário andino, meio ambiente, municípios.

\section{Introducción}

El presente artículo se desarrolla a partir de la formulación de la siguiente pregunta-problema de investigación: ¿̇el papel del derecho comunitario andino en la temática del medio ambiente busca generar impacto positivo o negativo desde las competencias de los municipios? El derecho comunitario andino es definido por el Tribunal de Justicia Comunitario como el sistema de normas que se interrelacionan con el objeto de regular la existencia y desarrollo del proceso de integración subregional y, en ese sentido, busca el cumplimiento de los objetivos del Acuerdo de Cartagena (Montes, 2012).

La temática en cuestión es pertinente si se tiene en cuenta que resulta importante plantear investigaciones con contenidos de la actualidad que incidan directamente en la enseñanza que brindan los docentes, el aprendizaje que reciben los estudiantes y la calidad de la educación ofrecida por el Estado a través de las universidades públicas y privadas existentes en el país. Los resultados que se presentan en este artículo son producto de un trabajo de análisis minucioso que procuró examinar un tema o aspecto concreto relacionado con la Comunidad Andina (CAN). Es importante anotar que la presente disertación es consecuencia del proyecto de investigación titulado "Las decisiones y resoluciones emitidas por la Comunidad Andina (CAN), en el marco de protección de derechos del medio ambiente en los municipios", cuyo propósito es analizar el papel 
del derecho comunitario andino en relación con el medio ambiente desde las competencias de los municipios.

\section{Metodología}

En lo que se refiere a la estructura metodológica del artículo planteado, cabe considerar que se trata de una investigación de tipo cualitativo, porque lo que se pretende es describir, comprender y profundizar sobre un tema en particular, que en este caso es el papel del derecho comunitario andino en la temática del medio ambiente desde las competencias de los municipios.

El alcance del artículo propuesto es descriptivo, porque se analizará y estudiará detalladamente la esencia del ordenamiento jurídico andino, en lo que tiene que ver con la protección y conservación del medio ambiente desde las entidades territoriales (municipios), de tal forma que se logren conocer los aspectos de mayor importancia sobre el tema objeto de estudio.

Se hará un análisis documental a partir de las fuentes del derecho interno (Constitución Política, leyes, doctrina y jurisprudencia), así como de las normas andinas, para obtener los mejores resultados posibles y poder compartirlos desde la academia.

\section{Naturaleza jurídica del derecho comunitario andino}

El derecho comunitario andino se origina y se nutre del derecho internacional público, pero se ha desprendido de este con "personalidad propia” (Poppe, 1985). Los tratados que dan vida al proceso de integración están sujetos, en su formalización y efectos, a las reglas del derecho de los tratados; no obstante, queda claro que el derecho de la integración no es un derecho extranjero en los países miembros (Andueza, 1985). 
De acuerdo con lo sostenido por Poppe (1985) y Andueza (1985), se puede intuir que el derecho comunitario andino es un conjunto de normas jurídicas común a las partes, creado para proteger a cada Estado miembro de la CAN de diferentes intereses en los que tiene parte esta organización de carácter internacional; por ello, no puede dársele el mismo trato que se le da al derecho extranjero (Blanco, 2015b).

El derecho comunitario es supranacional, y la supranacionalidad es el núcleo del derecho de la integración, ya que es el rasgo que produce la ruptura y diferencia con el derecho internacional común (Ortiz, 2002).

El Derecho Comunitario constituye un orden jurídico propio, distinto del Derecho Interno y del Derecho Internacional que deben aplicarse uniformemente en el territorio de todos los Estados miembros y, por lo tanto, tiene una jerarquía superior a los ordenamientos jurídicos nacionales. (Moreno, 1987, p. 55)

Así las cosas, se señala que el derecho comunitario andino es la base esencial del proceso de integración, habida cuenta que, al existir un conjunto de normas jurídicas que regulen a cada Estado miembro, estos quedan capacitados para generar un derecho común a toda el área de la organización internacional, obteniendo nuevas y mejores herramientas jurídicas que terminan favoreciendo en su totalidad a la CAN (Blanco, 2015c).

La tendencia mundial hacia la integración de los Estados ha venido estructurando un sistema de relaciones entre los sujetos participantes de los procesos de integración, relaciones que, según el entender de algunos autores, escapan a las regulaciones del derecho internacional y, por ende, requieren de un ordenamiento jurídico propio y especializado que algunos llaman derecho de la integración y otros, derecho comunitario (Sáchica, 1990). 
El derecho comunitario, en virtud de su supranacionalidad, se constituye en un ordenamiento jurídico propio y especializado, distinto del derecho interno y del derecho internacional común, que se inserta en los ordenamientos jurídicos nacionales con valor superior a la ley nacional a la que desplaza o sustituye en forma directa y automática - principios de aplicación directa y preeminencia- (Blanco, 2014).

Existe una ordenación jerarquizada de normas donde las superiores son la Constitución comunitaria, y las que ocupan un rango inferior, las derivadas o secundarias, que emanan de los órganos comunitarios; también se reconoce la importancia de estas normas en la conformación del bloque de constitucionalidad (Plata López y Yepes Ceballos, 2009).

De lo expuesto por los autores, se vislumbra que la supranacionalidad del derecho comunitario andino se sustenta en dos principios esenciales, a saber: por una parte, la aplicación directa de su normativa que produce efectos jurídicos en cada país miembro de la CAN, sin que se necesite algún tipo de complemento en materia de normatividad por parte del derecho interno; por otro lado, la preeminencia, que es la facultad que conserva el ordenamiento jurídico comunitario de prevalecer sobre una norma de derecho interno que se le contraponga (Blanco, 2013a).

Resulta de vital importancia estudiar los principios de primacía del derecho comunitario y eficacia directa, génesis que pauta un lineamiento de estructuración para una debida articulación de la organización ante la cual los Estados miembros ceden, de manera expresa, algunas de sus competencias. Este es el fundamento que permite la debida interacción entre los ordenamientos jurídicos internos de los Estados y la organización supranacional; en otras palabras, estos principios permiten que las decisiones emitidas por los órganos de la organización supranacional sean vinculantes para todos los Estados miembros (Cubillos et ál., 2014). 
De lo expresado por Cubillos et ál (2014), se comprende el carácter vinculante que tienen las decisiones emitidas por la CAN en los ordenamientos jurídicos internos de cada Estado que la componen pues, por una parte, se resalta la soberanía y las competencias de los países miembros, mientras que, por otra, se pone de manifiesto la aplicación de las decisiones proferidas por la CAN con base en las facultades asignadas. En otras palabras, entran en una especie de confrontación los poderes y autoridades, tanto de cada Estado miembro como de la organización, lo que se convierte en una importante puja jurídica, resultando tan solo admisible el bienestar de la sociedad civil (Pardo, 2014).

El concepto de primacía se entiende como aquel "complejo de normas jurídicas que disciplinan las comunidades de Estados y sus relaciones jurídicas con otros sujetos de derecho dando así un sistema jurídico institucional, nuevo, autónomo y especial" (Ulate, 2004, p. 153).

En este sentido, se considera importante tener una aproximación de lo que puede entenderse como primacía, ya que, partiendo de su definición, se puede llegar a una mayor comprensión de cómo operan algunas normas que contienen un mayor peso al momento de su aplicación en un determinado escenario jurídico (Blanco, 2013b).

Este sistema presenta como principal característica la de derivarse de los tratados de integración entre Estados, a partir de los cuales nace un sujeto u organismo de integración con vida propia, con la facultad de emitir una normativa a la que deben de sujetarse tanto los Estados miembros como sus ciudadanos (Giammattei, 1999).

Aquí se evidencia que la facultad de adoptar normas por parte del derecho comunitario andino, en principio, conlleva que se produzca una situación bastante original, toda vez que durante cierto lapso la materia viene a ser regulada por una norma interna, hasta que la CAN, haciendo uso de las 
competencias entregadas por los países miembros, entra a hacer su propia regulación y, entonces, dicha normativa empieza a ser de obligatorio cumplimiento para cada Estado que la integra.

Es así como el principio de primacía del derecho comunitario se entiende como el enunciado normativo que surge como resultado de las potestades cedidas por los Estados a la organización comunitaria (Rodríguez, 2016). Con base en dichas competencias, la organización supranacional puede generar normas jurídicas vinculantes para responder a los intereses comunes de los Estados (Ponce de León, 2001; Fernández de Casadevante, 2012; Lenaerts y van Nuffel, 2010; Saenz de Santa María et ál., 1999; Fairhurst, 1999).

En esta parte se afirma que, de conformidad con el alcance dado al principio de primacía del derecho comunitario andino, uno de sus elementos característicos consiste en su carácter absoluto, en la medida en que implica una limitación definitiva de cada Estado miembro en relación con sus derechos soberanos. Por esta razón, no es posible que prevalezca una norma interna en un caso determinado, porque sería incompatible con la esencia de la CAN (Patarroyo y Benavides, 2014).

De esta manera, el principio de primacía del derecho comunitario se sustenta en el concepto de soberanía que, aunque reside primigeniamente en los Estados de forma inalienable e imprescriptible, es transferida mediante un acto unilateral y uniforme a una organización supranacional para el fortalecimiento de la confianza regional y para enfrentar, de una manera más efectiva, los mayores problemas comunes a la luz del derecho internacional (Bou Franch y Cervera Vallterra, 2010).

Finalmente, se concluye que el derecho comunitario andino evidencia primacía, porque se trata de un conjunto de normas jurídicas organizado y coherente con el suficiente desarrollo y madurez para garantizar la eficacia 
de su normatividad, siendo capaz de producir efectos jurídicos en cada Estado miembro, sin que sea necesario ningún tipo de complemento normativo del derecho interno; de esta manera, se convierte en una fuente inmediata de derechos y obligaciones para todos aquellos a los que afecta.

\section{¿Para qué sirve y por qué existe el derecho comunitario andino?}

En principio, puede decirse que el derecho comunitario andino sirve y existe por la necesidad que vieron algunos países de la región suramericana de fortalecer las relaciones jurídicas, a través de la conformación de un proceso de integración que, además de estrechar lazos de amistad entre pueblos hermanos, busca robustecer los aspectos económicos, políticos y sociales de cada Estado, con el fin de generar progreso y bienestar a sus ciudadanos.

El derecho comunitario andino sirve también para lograr normas homogéneas en cada Estado que hace parte de la CAN, en aras de mejorar su desarrollo, mediante la realización de una serie de actividades que permitan un intercambio intracomunitario, la preservación de conductas acordes con los compromisos asumidos y el avance en la conformación de un mercado común que se encuentre regulado por el ordenamiento jurídico, de tal forma que, frente a cualquier controversia, la normativa andina ingrese a resolverla manteniendo siempre el equilibrio.

Además, el derecho comunitario andino existe porque se requiere generar armonización legislativa, es decir, surge la necesidad de tomar las leyes de cada Estado miembro de la CAN para hacer un compendio, de tal forma que existan mayores herramientas jurídicas garantes del proceso de integración y que estas no choquen entre sí cuando se vaya a resolver un pleito jurídico entre las partes. 
Se cita el artículo de revista titulado el Medio Ambiente en el Marco del Derecho Comunitario Andino y la Legislación Colombiana, donde su autora Laura Lizeth Mancera Rodríguez sobre esta temática, aporta lo enunciado a continuación:

Si bien existe cierta convergencia normativa entre Colombia y la CAN para el logro del establecimiento de un régimen común, falta armonizar un mayor número de normas de carácter ambiental entre sí, y con normas de otro carácter que inciden como el penal, el comercial etc., y con tratados de carácter internacional pues "resulta fundamental coordinar estas acciones, con aquéllas previstas en tratados internacionales aplicables en el área, suscritos por varios o todos los países andinos" (Ponce de León, 2001, p. 140), ya que el vacío legislativo relativiza la protección y conservación del medio ambiente y conlleva a que se difiera en sus usos, aprovechamientos y a que se menoscabe la eficiencia de las normas. Puesto que se permite que los países miembros jueguen con las normas (Puyo, 2006).

Los Estados muchas veces son refractarios a aceptar sistemas de aplicación de normas comunitarias que pongan límites a su capacidad de acción o autonomía interna frente a los asuntos que suscite el medio ambiente. Es por esto que los obstáculos de carácter político juegan un rol importante, ya que los Estados se resisten a establecer procesos de fiscalización y control que limiten su libertad de acción soberana (Juste, 1999). Por lo que es necesario que los países miembros entiendan que la CAN exige por parte de todos éstos el sometimiento a un mismo derecho en aquellas materias en las que han realizado la transferencia del ejercicio de competencias en favor de la Comunidad. (Mancera, 2015, pp. 33-37)

El derecho comunitario andino sirve y existe por la necesidad de tener un sistema propio para resolver conflictos, ya que, en un primer momento, el Acuerdo de Cartagena no contaba con un sistema de solución de 
controversias propio, sino que se regía por el procedimiento de solución de controversias pactado en el Tratado de Montevideo de 1960, que básicamente disponía la negociación, la conciliación y el arbitraje (Rodríguez, 2016).

\section{Marco Normativo de la Comunidad Andina (CAN) y de Colombia Referente al Medio Ambiente en los Municipios}

Al remitirnos al orden constitucional, encontramos que la Carta Política de Colombia dispone en su artículo 9 lo siguiente:

Las relaciones exteriores del Estado se fundamentan en la soberanía nacional, en el respeto a la autodeterminación de los pueblos y en el reconocimiento de los principios del derecho internacional aceptados por Colombia. De igual manera, la política exterior de Colombia se orientará hacia la integración latinoamericana y del Caribe

Se observa que la Norma Superior consagra las relaciones exteriores del Estado colombiano y los procesos de integración con otros países, lo que se considera que es con el propósito de fijar algunas metas que en este caso obedecen a la defensa del medio ambiente, en aras de protegerlo y conservarlo para el disfrute de las nuevas generaciones.

Lo anteriormente expuesto cobra mayor fuerza cuando la Constitución Política de 1991 establece en su Preámbulo lo siguiente:

El pueblo de Colombia, en ejercicio de su poder soberano [...] y comprometido a impulsar la integración de la comunidad latinoamericana [...] Pudiendo mencionarse para el estudio que nos ocupa, la Comunidad Andina - CAN, como una organización de carácter internacional que busca estrechar lazos de amistad entre países vecinos, facilitando las relaciones diplomáticas y permitiendo un fortalecimiento a nivel suramericano. (Énfasis añadido.) 
Ahora bien, al remontarnos al orden legal, iniciaremos citando la Ley 99 de 1993:

Artículo 10. PRINCIPIOS GENERALES AMBIENTALES. La política ambiental colombiana seguirá los siguientes principios generales: [...] 4 . Las zonas de páramos, subpáramos, los nacimientos de agua y las zonas de recarga de acuíferos serán objeto de protección especial. [...] 10. La acción para la protección y recuperación ambientales del país es una tarea conjunta y coordinada entre el Estado, la comunidad, las organizaciones no gubernamentales y el sector privado.

Se considera que este mandato legal propende por la protección del medio ambiente en todos sus ámbitos, como parte de un proceso de desarrollo económico y social del país, orientado en los principios universales del derecho, contenidos en distintas normativas nacionales e internacionales. Una vez realizado este estudio de orden constitucional y legal, nuestra atención se centrará en las decisiones y resoluciones emitidas por la CAN en el marco de protección de derechos del medio ambiente y sus finalidades en los municipios; no obstante, antes de revisar tales pronunciamientos, presentaremos algunas generalidades sobre dicha organización.

La CAN inició con la suscripción del Acuerdo de Cartagena, el 26 de mayo de 1969. Dicho Acuerdo indica en su artículo 128 lo siguiente: "Los países miembros emprenderán acciones conjuntas que permitan un mayor aprovechamiento de sus recursos naturales renovables y no renovables y la conservación y mejoramiento del medio ambiente".

Entre tanto, dentro de la normativa emitida por la CAN, se cita la Decisión 435 de fecha 11 de junio de 1998, que sostiene en su artículo 1 lo siguiente: "Crear el Comité Andino de Autoridades Ambientales (CAAAM), que 
estará conformado por las autoridades nacionales responsables del medio ambiente de cada país miembro".

No podemos culminar este marco normativo sin mencionar algunas de las decisiones y resoluciones emitidas por la CAN en el marco de protección de derechos del medio ambiente, toda vez que tales pronunciamientos nos permiten conocer a profundidad las gestiones realizadas por esta organización internacional en torno a la preservación y cuidado del medio ambiente en cada uno de los países miembros.

En su tesis doctoral titulada La Descentralización Territorial en el marco de la Comunidad Andina (CAN), Blanco (2015a) resalta algunas decisiones importantes emitidas por esta organización, entre las que se pueden mencionar:

- Con la Decisión 763 de 2011 se emite la Estrategia Andina para la Gestión Integrada de los Recursos Hídricos, entendiéndose por dicha gestión el proceso sistemático para el desarrollo, asignación y monitoreo de los usos del agua, de acuerdo con objetivos sociales, económicos y ambientales que buscan el desarrollo sostenible.

- La biodiversidad de los países andinos tiene una importancia enorme a nivel global; además, es fundamental para sustentar el desarrollo sostenible de los Estados andinos. Por eso, la CAN, mediante la Decisión 523 de 2002, emitió la estrategia regional de biodiversidad para los países del trópico andino (Blanco, 2015a).

- Por otra parte, la Decisión 713 de 2009 modifica la Decisión 591 de 2004: Estrategia Andina para la Prevención y Atención de Desastres. De conformidad con sus considerandos encontramos lo siguiente: El Acuerdo de Cartagena establece que, para promover el desarrollo equilibrado y armónico de los Países Miembros en condiciones de equidad, mediante la integración y la cooperación económica y social, así 
como para procurar un mejoramiento persistente en el nivel de vida de los habitantes de la subregión, se emplearán, entre otras, acciones para la conservación y aprovechamiento de los recursos naturales y del medio ambiente.

- La Decisión 762 de 2011 aprueba la ejecución del Proyecto "Programa de Adaptación al Cambio Climático en la Región Andina”. De conformidad con sus considerandos, encontramos lo siguiente:

Para alcanzar los objetivos de desarrollo equilibrado y armónico de los Países Miembros en condiciones de equidad, el Acuerdo de Cartagena establece que los Países Miembros emprenderán acciones conjuntas para el aprovechamiento y la conservación de los recursos naturales y del medio ambiente.

Una vez consultada la página oficial de la Comunidad Andina, se encuentra que, con la finalidad de hacer frente a la minería ilegal y buscar acciones coordinadas para proteger los recursos naturales, promover canales más fluidos de cooperación entre los países, así como para realizar actividades de prevención y control de dicho fenómeno en beneficio del medio ambiente, la vida y la salud de los ciudadanos de la subregión, los países miembros de la CAN decidieron realizar un trabajo conjunto para enfrentar este problema de carácter multidimensional, que atenta contra la paz, la seguridad, la gobernabilidad, la economía y la estabilidad.

Como resultado de este esfuerzo comunitario, mediante la Decisión 774 de 2012 se aprobó la Política Andina de Lucha contra la Minería Ilegal y se creó el Comité Andino contra la Minería Ilegal, trazándose como objetivo principal enfrentar de manera integral, cooperativa y coordinada la minería ilegal y actividades conexas, que atentan contra la seguridad, la economía, los recursos naturales, el medio ambiente y 
la salud humana, y que a su vez provoca daños irreversibles, en la salud de la población, el medio ambiente y los recursos naturales. La Gaceta Oficial del Acuerdo de Cartagena también nos presenta la Decisión 596 de 2004, por la cual se crea el Consejo de Ministros de Medio Ambiente y Desarrollo Sostenible de la CAN, que consagra en su artículo 2 lo siguiente: "El Consejo de Ministros de Medio Ambiente y Desarrollo Sostenible de la Comunidad Andina estará conformado por las máximas autoridades ambientales y de desarrollo sostenible de cada país miembro".

Se resalta el propósito e importancia de implementar una Agenda Ambiental y consagrar y regular aspectos propios del medio ambiente como el recurso hídrico, la prevención y atención de desastres, el cambio climático, la biodiversidad, los recursos genéticos y los plaguicidas químicos, para cuidar, proteger y salvaguardar el medio ambiente y los recursos naturales presentes en la región (Mancera, 2015).

En contexto, lo que busca la CAN, al proferir este tipo de decisiones, es brindar mayores instrumentos jurídicos a cada Estado miembro en el marco de protección de derechos del medio ambiente, por lo que nuestra atención se centrará en estudiarlas detenidamente para determinar si tales decisiones producen las finalidades deseadas en los municipios.

\section{Papel, importancia y finalidad del derecho comunitario andino en la temática del medio ambiente frente a los municipios}

Se entiende por medio ambiente toda la red de interacciones geológicas y biológicas que determinan la relación entre la vida y el planeta Tierra, además del conjunto de relaciones fundamentales que existen entre el 
mundo material o biofísico (atmósfera, litosfera, hidrosfera, biosfera) y el mundo sociopolítico (Tena y Hernández, 2014).

Díaz (2001), catedrático de Ecología de la Universidad Complutense de Madrid, dice que la expresión medio ambiente en castellano es una redundancia, ya que el ambiente es el entorno, el medio donde transcurre la vida. En general, la sociedad occidental tiene claro que en el término medio ambiente están recogidos el medio físico (ríos, mares y océanos, valles y montañas, etc.) y biótico (animales, plantas, hongos, etc.), pero es menos frecuente que el ciudadano sepa que también forman parte del mismo el medio sociocultural y económico, que a través de la actividad humana condiciona a los otros y a su vez influye de manera directa en las generaciones venideras (Ramos García-Serrano y Sánchez Maldonado, 2013).

A partir de las distintas definiciones de medio ambiente que nos presentan los autores, se plantea el siguiente interrogante: ¿Cuál es el papel del derecho comunitario andino en la relación medio ambiente-municipios? Se encuentra una primera respuesta cuando se afirma que el papel del derecho comunitario andino en dicha relación consiste en facilitar diversas normas jurídicas que protejan a toda costa los ecosistemas a nivel local, atendiendo al grado de autonomía que tienen las entidades territoriales (municipios), partiendo también de las funciones y competencias que se encuentran asignadas a cada autoridad. Por ejemplo, para el caso de Colombia, los alcaldes pueden regular ciertas conductas mediante la expedición de decretos, mientras que los concejos lo hacen profiriendo acuerdos.

El papel del derecho comunitario andino en la relación medio ambiente-municipios, también es regular aspectos propios del medio ambiente como el recurso hídrico, la prevención y atención de desastres, el 
cambio climático, la biodiversidad, los recursos genéticos y los plaguicidas químicos, para cuidar, proteger y salvaguardar el medio ambiente y los recursos naturales presentes en la región (Mancera, 2015).

El papel del derecho comunitario andino en la relación medio ambiente-municipios se resume en que la población tiene el derecho a disfrutar de un ambiente sano, pero con la responsabilidad de cuidarlo y protegerlo, contando con acciones de carácter constitucional.

En torno a lo anteriormente expuesto, y con el propósito de entrar más en materia, surgen los siguientes interrogantes:

\section{¿Por qué es importante el derecho al medio ambiente desde la CAN?}

Es importante porque todo ser humano tiene derecho a disfrutar de un medio ambiente adecuado, como una condición previa para la completa realización de otros derechos, tales como la vida, la salud, la alimentación y el agua. Estos deben ser garantizados por todas las organizaciones del mundo, entre ellas, la ONU, la OEA y, por supuesto, la CAN.

\section{¿Por qué es importante que los municipios, especialmente los alcaldes, cumplan con las decisiones de la Comunidad Andina en el marco ambiental?}

Teniendo en cuenta que las decisiones son disposiciones aprobadas por la Comisión de la CAN por consenso de todos los países miembros de este organismo subregional, es importante que los municipios, especialmente los alcaldes, las cumplan por las siguientes razones:

1. Porque tienen carácter vinculante para los países (Colombia, Perú, Bolivia y Ecuador), toda vez que se constituyen en normas supranacionales, a menos que las mismas normas establezcan que el Estado debe proferir disposiciones internas. 
2. Porque promueven el bienestar armónico y equilibrado de cada entidad territorial en materia de protección del medio ambiente.

3. Porque son producto de un proceso de integración y cooperación para proteger los páramos, las fuentes hídricas y los ecosistemas en general de cada pueblo.

4. Porque procuran siempre un mejoramiento en el nivel de vida de los ciudadanos, al incorporar prácticas ambientales de impacto social.

Según Macías (1998), el derecho ambiental hace referencia a varios aspectos: la protección de la naturaleza, o recursos naturales renovables; la contaminación; el ordenamiento territorial; la protección de las identidades culturales de las etnias; el sistema institucional de la administración y control, entre otros aspectos, que van desde lo nacional hasta lo internacional (García y Fino, 2014).

Ahora bien, otro aspecto que centra la atención en esta investigación es el calentamiento global que, de acuerdo con González (2007), es el fenómeno ocasionado por los cambios promedio del aumento en la temperatura de la atmósfera terrestre y de los océanos en las últimas décadas.

Sobre el calentamiento global se considera importante indicar que se trata de un fenómeno que se ha venido incrementando día a día, debido a diversas causas. Una de ellas, quizás la principal, es la irresponsabilidad del ser humano cuando producto de su inconciencia tiende a quemar indiscriminadamente los páramos y bosques, contamina los ríos y quebradas y malgasta el agua potable regando cultivos o lavando vehículos, ignorando las consecuencias futuras de todas estas acciones (Gallego, 2014).

Por su parte, Tapiador (2015) resalta que, según los científicos del Panel Intergubernamental sobre el Cambio Climático (IPCC), el calentamiento global actual está motivado por el incremento observado en la 
concentración en el aire de ciertos gases, como el dióxido de carbono. Dicho incremento se debe a las actividades humanas, fundamentalmente a la quema de combustibles fósiles, como el petróleo, el gas y el carbón (Tapiador, 2015).

De lo expresado por los autores surge el siguiente interrogante: ¿Por qué el calentamiento global es respuesta en la relación medio ambiente y municipios? Porque la relación que tenemos los ciudadanos con el medio ambiente en cada municipio hasta el momento no ha sido la mejor, resultando importante empezar en cambiarla, ya que el planeta se encuentra en riesgo y, si bien el calentamiento global hasta el momento no está fuera de control, pronto podría estarlo, a raíz de cada acto irresponsable cometido por los seres humanos; por ejemplo, cuando se talan y se queman indiscriminada los bosques o cuando se contaminan las fuentes hídricas (Humbarita, 2015).

Se concluye que el papel, importancia y finalidad del derecho comunitario andino en la temática del medio ambiente y de los municipios son bastante amplios, porque involucran distintos aspectos por estudiar, como los recursos naturales renovables y no renovables, las fuentes hídricas, la atención y prevención de desastres, el cambio climático, la biodiversidad, el calentamiento global, el cuidado de los páramos, entre otros. Estos deben contar siempre con una protección jurídica especial interna y externa (Valderrama et ál., 2018).

Ahora bien, en este apartado surge la necesidad de hacer una aproximación a los conceptos de gobernanza y paradiplomacia, porque pueden definirse desde un punto de vista jurídico y van de la mano con el actuar administrativo y político por parte de los alcaldes y los concejos en los municipios: mientras la gobernanza se refiere principalmente a un 
conjunto de actuaciones internas, la paradiplomacia se encamina más a distintas acciones por fuera del país (Palomares y Calonje, 2015).

Sobre el concepto de gobernanza, se puede decir que se trata de un paradigma emergente que Aguilar (2006) ha definido como "el proceso mediante el cual los actores de una sociedad deciden sus objetivos de convivencia fundamentales y coyunturales y las formas de coordinarse para realizarlos: su sentido de dirección y su capacidad de dirección" (Aguilar, 2006, p. 90).

Teniendo ya una noción de lo que en términos generales es la gobernanza, nos permitimos dar un salto a la definición de paradiplomacia, con el propósito de establecer la relación existente entre estos dos conceptos, que van de la mano y que resultan importantes dentro de la investigación adelantada.

Si bien en relación con la paradiplomacia hay mucha literatura, aún no ha sido plenamente definida. Aunque el análisis del fenómeno inició desde la década de los años setenta, se limitó a una descripción de las actividades internacionales de las regiones, más que a un debate conceptual (Zeraqui, 2016). Es de vital importancia entender que la gobernanza y la paradiplomacia permiten promover el papel del derecho comunitario andino en relación con el medio ambiente en los municipios por las siguientes razones:

1. Se generan escenarios internos y externos que apuntan hacia el establecimiento de un compendio normativo en materia ambiental, que fortalece jurídicamente a nuestro país en todos sus niveles de gobierno, es decir, a nivel nacional, departamental y municipal, toda vez que se cuenta con mayores instrumentos en el campo del Derecho, tales como las decisiones y resoluciones emitidas por la CAN (Barragán, 2016). 
2. Se propende por la creación de convenios y tratados entre los países que hacen parte de la CAN, a través de normas nacionales e internacionales, de tal forma que no exista dispersión jurídica entre el derecho comunitario andino y las normas internas de cada país miembro de la organización, evitando una posible desprotección jurídica en materia ambiental (Cortés, 2016).

\section{Conclusiones}

Es evidente que el papel del derecho comunitario andino en relación con el medio ambiente busca generar un impacto positivo desde las competencias de los municipios, porque, de conformidad con el Acuerdo de Cartagena, las normas jurídicas comunitarias tienen carácter vinculante, es decir, son de obligatorio cumplimiento y prevalecen sobre las normas internas de cada Estado miembro.

El derecho comunitario andino es un conjunto de normas y disposiciones jurídicas que refuerza la protección y conservación del medio ambiente, sin usurpar las competencias de los municipios, ya que entra a corregir las posibles omisiones que puedan presentar las autoridades ambientales (Ministerios de Ambiente y Corporaciones Autónomas Regionales) de cada Estado miembro a nivel nacional.

El derecho comunitario andino se constituye en un sistema propio para resolver controversias jurídicas de carácter ambiental que se presenten en los municipios, lo que significa un avance importante para los Estados parte, puesto que, en un principio, el Acuerdo de Cartagena no contaba con dicho sistema, lo que dificultaba la correcta administración de justicia. El papel del derecho comunitario andino en la temática del medio ambiente desde las competencias de los municipios supone tener en cuenta los aspectos económico, político, social y jurídico, toda vez que cada 
Estado miembro de la CAN tiene su propia forma de gobierno y, por tanto, su desarrollo institucional opera de manera diferente.

\section{Referencias}

\section{Doctrina}

Aguilar, L. F. (2014). Las dimensiones y los niveles de gobernanza. Cuadernos De Gobierno y Administración Pública, 1(1), 11-36. https://doi.org/10.5209/rev CGAP.2014.v1.n1.45156

Andueza, J. (1985). La interpretación prejudicial y el Tribunal de Justicia del Acuerdo de Cartagena. En: Instituto para la Integración de América Latina (INTAL), El Tribunal de Justicia del Acuerdo de Cartagena (p. 85). INTAL.

Barragán, D. (2016). La construcción de la mentalidad democrática como necesidad en el posconflicto. Via Inveniendi Et Iudicandi, 11(1), 37-57. https://doi.org/10.15332/s1909-0528.2016.0001.06

Bou Franch, V. y Cervera Vallterra, M. (2010). Normativa y jurisprudencia básica del derecho de la Unión Europea. Tirant lo Blanch.

Blanco, C. (2013a). Algunas propuestas frente a la crisis de legitimidad de la comunidad andina. Análisis Político, 26(78), 141-155.

Blanco, C. (2013b). La Comunidad Andina en el marco de lo jurídico y político en Revista Prolegómenos, 16(31), 173-188.

Blanco, C. (2014). La crisis de la comunidad andina. Revista de Derecho, 42, 1-32.

Blanco, C. (2015a). La Descentralización Territorial en el Marco de la Comunidad Andina (CAN) [tesis para optar al Doctorado en Derecho, Universidad Santo Tomás]. Repositorio USTA. http://dx.doi.org/10.15332/tg.doc.2015.00011

Blanco, C. (2015b). La influencia positiva de la CAN en la descentralización territorial colombiana. Revista Opinión Jurídica, 14(27), 161-174.

Blanco, C. (2015c). La conexión entre descentralización territorial colombiana e integración andina. Análisis Político, 28(84), 207-216.

https://doi.org/10.15446/anpol.v28n84.54647

Revista IUSTA

ISSN: 1900-0448 | e-ISSN: 2500-5286 | DOI: https://doi.org/10.15332/25005286

N. ${ }^{\circ} 54$ | enero-junio de 2021 
Colombia. Ley 99 de 1993. Por la cual se crea el Ministerio del Medio Ambiente, se reordena el Sector Público encargado de la gestión y conservación del medio ambiente y los recursos naturales renovables, se organiza el Sistema Nacional Ambiental, SINA y se dictan otras disposiciones. Diciembre 22 de 1993. DO núm. 41146.

Cortés, S. (2016). Derechos humanos en las políticas de paz y posconflicto en Colombia. Via Inveniendi Et Iudicandi, 11(1), 129-145. https://doi.org/10.15332/s1909$\underline{0528.2016 .0001 .03}$

Cubillos, A., Pachón, J. y López, C. (2014). Los principios de primacía y eficacia directa del derecho comunitario andino: conceptualización, desarrollo y aplicación.

Revista Jurídicas, 11(2), 148-169. http://juridicas.ucaldas.edu.co/downloads/Juridicas11(2) 9.pdf

Díaz Pineda, F. (2001). Ecosistemas y biodiversidad. En P. García Barreno (dir.), La ciencia en tus manos (2. ${ }^{\mathrm{a}}$ ed.) (pp. 285-312). Espasa Calpe.

Fairhurst, J. (1999). Law of the European Union. Pearson.

Fernández de Casadevante Romani, C. F. (2012). Derecho de la Unión Europea. Nociones básicas. Dilex.

Gallego, J. (2014). Paradoja y complejidad de los derechos humanos en la sociedad moderna. Sentido y comunicación. Revista IUSTA, 1(40), 143-165.

https://doi.org/10.15332/s1900-0448.2014.0040.01

García, M. y Fino, G. (2014). Los impuestos territoriales en Colombia y la inequidad social, cla voluntad de la clase dominante erigida en ley? Revista IUSTA, 2(41), 61-75. https://doi.org/10.15332/s1900-0448.2014.0041.04

Giammattei, J. A. (1999). Guía concentrada de la integración centroamericana. Corte Suprema de Justicia.

González, C. (2007, abril). Calentamiento global [presentación de diapositivas]. http://agricultura.uprm.edu/calentamiento/pdf/Calentamiento\%2oglobal.pdf

Juste, J. (1999). Derecho Internacional del Medio Ambiente. McGraw Hill.

Humbarita, J. (2015). Derecho Constitucional Hispanoamericano frente a la realidad institucional, manifiesta divergencia. Revista IUSTA, 2(43), 91-118. https://doi.org/10.15332/s1900-0448.2015.0043.03

\section{Revista IUSTA}

ISSN: 1900-0448 | e-ISSN: 2500-5286 | DOI: https://doi.org/10.15332/25005286

N. 054 | enero-junio de 2021 
Lenaerts, K. y Van Nuffel, P. (2010). European Union Law. Sweet and Maxwell.

Macías Gómez, L. (1998). Introducción al derecho ambiental. Legis.

Mancera, L. (2015). El medio ambiente en el marco del derecho comunitario andino y la legislación colombiana [tesis de pregrado en Derecho, Universidad Santo Tomás]. Repositorio Institucional de la Universidad Santo Tomás.

https://hdl.handle.net/11634/1992

Montes, M. (2012). Efectos Reglamentarios y Jurisdiccionales del Derecho Comunitario Andino Sobre el Derecho Administrativo Colombiano [tesis de grado de la Maestría en Derecho Administrativo, Universidad del Rosario]. Repositorio Institucional EdocUR.

https://repository.urosario.edu.co/bitstream/handle/10336/3929/527163962012.pdf? sequence $=1$

Moreno Loayza, G. (1987). El Tribunal de Justicia del Acuerdo de Cartagena como medio jurídico de solución de controversias. Tribunal de Justicia del Acuerdo de Cartagena.

Ortiz Ahalf, L. (2002). Derecho comunitario y derecho internacional. Jurídica. Anuario del Departamento de Derecho de la Universidad Iberoamericana, 32, 11-23.

Palomares, J. y Calonje, N. (2015) Tratados de libre comercio Colombia-Asia: cuestión preliminar y perfiles de negociación. Revista IUSTA, 2(43), 17-41.

https://doi.org/10.15332/s1900-0448.2015.0043.06

Pardo, N. (2014). Un recorrido por los derechos colectivos en la jurisprudencia argentina. Revista Via Inveniendi et Iudicandi, 9(1), 32-49. http://revistas.usantotomas.edu.co/index.php/viei/article/view/1338/1540

Patarroyo, S. y Benavides, P. (2014). Rupturas asignificantes: revisiones críticas en torno al Derecho. Revista Via Inveniendi et Iudicandi, 9(1), 7-31. https://doi.org/10.15332/s1909-0528.2014.0001.01

Ponce de León, E. (2001). Temas de derecho comunitario ambiental andino (1. ${ }^{\mathrm{a}}$ Ed.). Universidad Externado de Colombia.

Poppe, H. (1985). Disposiciones jurídicas vigentes en el Tribunal de Justicia del Acuerdo de Cartagena. El Tribunal.

Revista IUSTA

ISSN: 1900-0448 | e-ISSN: 2500-5286 | DOI: https://doi.org/10.15332/25005286

N. 054 | enero-junio de 2021 
Puyo, G. (16 de mayo del 2006). La importancia de la Comunidad Andina de Naciones. Institutos de estudios geoestratégicos y de asuntos políticos, Universidad Militar de la Nueva Granada.

Plata, L. y Yepes, D. (2009). Naturaleza Jurídica de las Normas Comunitarias Andinas. Revista de Derecho, 31, 196-223. http://www.scielo.org.co/scielo.php?script=sci arttext\&pid=S0121$\underline{86972009000100008}$

Ramos García-Serrano, C. y Sánchez Maldonado, V. (eds.). (2013). Manual de medio ambiente. Retos ambientales y cooperación para el desarrollo. Alianza por la Solidaridad y Agencia Española de Cooperación para el Desarrollo (AECID).

Rodríguez, C. (2016). La autonomía del derecho comunitario andino y su relación con el derecho internacional. Revista de la Secretaría del Tribunal Permanente de Revisión, 4(8), 224-245. https://doi.org/10.16890/rstpr.a4.n8.p224.

Rodríguez, E. (2016). El pasaje del estado y el derecho a la postmodernidad. Revista Via Inveniendi et Iudicandi, 11(2), 11-37. https://doi.org/10.15332/s1909$\underline{0528.2016 .0002 .01}$

Sáchica, L. (1990). Introducción al derecho comunitario andino. Temis.

Sáenz de Santa María, P. A., González, J. y Fernández, B. (1999). Introducción al derecho de la Unión Europea. Eurolex.

Tapiador, F. (2015). Tu compromiso por el medio ambiente. Fundación Mapfre. https://previa.uclm.es/servicios/prevencion/CADS_pub/doc/EL\%20CALENTAMI ENTO\%20GLOBAL.pdf

Tena, E. y Hernández, A. (2014). Nuestro medio ambiente: cápsulas facilitadoras para su aprendizaje en la realidad dominicana. Centro Cultural Poveda. http://209.177.156.169/libreria cm/archivos/pdf 697.pdf

Ulate, E. (2004). Integración regional y derecho agrario comunitario europeo y centroamericano. Editorial Chico.

Valderrama, I., Téllez, R. y Blanco, C. (2018). La incertidumbre de las victimas dentro del Acuerdo para la Construcción de una paz estable y duradera. En J. Carvajal (ed.), Tendencias actuales de los derechos humanos y el derecho internacional humanitario en Colombia (pp. 85-104). Ediciones USTA. https://doi.org/10.15332/li.lib.2018.00009

Revista IUSTA

ISSN: 1900-0448 | e-ISSN: 2500-5286 | DOI: https://doi.org/10.15332/25005286

N. 054 | enero-junio de 2021 
Zeraqui, Z. (2016). Para entender la paradiplomacia. Desafios, 28(1), 15-34.

https://revistas.urosario.edu.co/xml/3596/359643444001/3596434444001 visor jats.pdf

\section{Decisiones emitidas por la Comunidad Andina (CAN)}

Decisión 435 de 1998

Decisión 523 de 2002

Decisión 596 de 2004

Decisión 713 de 2009

Decisión 762 de 2011

Decisión 763 de 2011

Decisión 774 de 2012 